\title{
International R\&D Spillovers and Asset Prices
}

\author{
Federico Gavazzoni and Ana Maria Santacreu*
}

December 2014

\begin{abstract}
We document that international $R \& D$ spillovers through trade in varieties is a major driver of asset prices. We find that country pairs that share more R\&D have more correlated stock market returns and less volatile exchange rates. Moreover, we show that countries that depend more heavily on their trading partner's R\&D have currencies that tend to pay a positive excess return. We develop an endogenous growth model of innovation and international technology diffusion that rationalizes our empirical findings. A calibrated version of our model matches several important asset pricing and quantity moments, thus alleviating several of the classic quantityprice puzzles of the international macroeconomic literature.
\end{abstract}

${ }^{*}$ Contact: Federico Gavazzoni is at INSEAD. Email: federico.gavazzoni@insead.edu; Ana Maria Santacreu is at the Federal Reserve Bank of Saint Louis and INSEAD. Email: anamaria.santacreu@insead.edu. This paper previously circulated with the title "International Comovement through Endogenous Long Run Risk". We appreciate the helpful comments of Bernard Dumas, Antonio Fatas, Ilian Mihov, Adrian Verdelhan, and Gianluca Violante, and the participants of the 2014 SED meeting in Toronto. All errors are our own. 


\section{Introduction}

The international macroeconomics and finance literature has had a hard time reconciling the joint dynamics of equilibrium quantities and asset prices. Among the most significant puzzles, and contrary to the prediction of standard real business cycle models, cross country correlations in macroeconomic quantities are significantly lower than cross country correlation in asset prices, exchange rates are volatile and appear to be disconnected from fundamentals, and uncovered interest parity is systematically violated. ${ }^{1}$

In this paper, we argue that international $R \& D$ spillovers through trade in varieties could be an important driver of international equilibrium quantities and asset prices. Using highly disaggregated bilateral trade data, we document the following empirical regularities. First, country pairs that share more $R \& D$ by trading a higher number of varieties have more correlated stock market returns. Second, country pairs that share more R\&D have less volatile exchange rates. Third, countries that depend more heavily on their trading partner's R\&D have currencies that tend to pay a positive excess return. These patters are robust to controlling for the overall level of trade across each country-pair, suggesting that international $R \& D$ spillovers play a crucial role in the joint determination of international quantities and asset prices.

We build a two-country endogenous growth model of innovation and international technology diffusion through trade in varieties that rationalizes our empirical findings. Growth in each country is driven by the accumulation of technology through endogenous innovation. The main assumption is that technology, which is embodied in intermediate goods, spread across countries through international trade. As a result, the productivity level of a country depends not only on its own innovations, but also on the foreign innovations embodied in the imported intermediate products. In each country, a representative consumer takes consumption and saving decisions. Preferences are recursive, so that consumers care for the timing of resolution of uncertainty and fear variation in long-run future prospects of the economy. Endogenous innovation together with recursive preferences make the equilibrium growth path risky, through its effect on the present discounted value of future profits of all the firms in the economy.

We show that while realized growth in each country is the main driver of the modest cross country comovements in macroeconomic quantities, future expected global growth is responsible for the high cross country correlation in asset prices. For future expected global growth to have substantial quantitative impact on asset prices, agents in our model must fear variations in the long-run prospects of the economy which, in turn, depend both

\footnotetext{
${ }^{1}$ For a comprehensive summary of the literature see, among others Obstfeld and Rogoff (2000), Lewis (1995), and references therein.
} 
on domestic and foreign innovation.

Our endogenous growth mechanism works as follows. R\&D drives a small and persistent component in equilibrium growth rates. International diffusion through trade in varieties makes this component common across countries. The intuition is that a technology shock in the domestic country affects not only the incentive to innovate in that country, but also the incentives to innovate abroad and in turn impacts the prospects of global growth. Therefore, a short-run technology shock in the domestic country has a long-run effect on the dynamics of growth rates both in the domestic and in the foreign economy. We close the model with the assumption of complete international financial markets. Because of recursive preferences, the common persistent component generated by innovation and international $\mathrm{R} \& \mathrm{D}$ spillovers has a large effect on asset risk premia.

We calibrate the model to match our empirical findings. A crucial parameter governs the level of intensity through which domestic innovations diffuse internationally and can therefore be used in the production of foreign goods. Consistently with the predictions of the model, we find that equilibrium macroeconomics quantities are only mildly correlated across countries since they are mostly driven by short-run shocks. On the contrary, asset prices are mostly driven by the long-run future prospects of the economy. Given our international risk sharing mechanism, stock returns and interest rates are highly correlated across countries, and more so for stronger international R\&D spillovers. Exchange rates are volatile, and more so for a weaker international R\&D spillovers. Finally, currencies of countries that depend more heavily on their trading partner's R\&D carry a positive risk premium as they are exposed to R\&D risk. The more a country depends on foreign R\&D, the larger the risk premium associated with its currency.

Our paper is related to several strands on literature. First, the literature on endogenous growth through innovation. In our model, technological progress increases with the number of intermediate goods that embody technology. Kung and Schmid (2011) extend Romer (1990) to include recursive preferences and reproduce asset prices dynamics that are consistent with the empirical literature. We develop our model along these lines, and extend it to an international setting to capture our novel empirical findings on the relation between trade, R\&D, and asset prices.

The second strand of literature is the one on technology adoption and innovation through international trade in varieties, as in Broda, Greenfield, and Weinstein (2006) and Santacreu (2014). Using highly disaggregated trade data, these papers find that adoption of foreign innovations through trade in varieties has an effect on the growth rate of a country. However, they do not discuss the asset pricing implications of their mechanism, which is one of the main contributions of our work. 
Finally, the paper is related to the literature on asset pricing with long run risk, starting from the seminal one-country model of Bansal and Yaron (2004), and later applied to the international setting by Bansal and Shaliastovich (2009), Colacito and Croce (2011), and Colacito and Croce (2013). While these papers specify global long-run risk exogenously, our model shows how such risk - highly persistent within countries and highly correlated across countries - arises endogenously through innovation and international diffusion of R\&D. Methodologically, our paper is closely related to recent work byCroce, Nguyen, and Schmid (2013) which focuses on the role of robustness and contagion in the global diffusion of entropy shocks. Unlike them, we focus on the empirical link between trade, R\&D, and asset prices in the context of an endogenous growth model with recursive preferences.

The rest of the paper is organized as follows. Section 2 shows our main empirical findings and Section 3 describes our baseline model. Section 4 provides a description of the main mechanism at work, while Section 5 presents the calibration and the quantitative results. Finally, Section 6 concludes.

\section{Innovation, Trade, and Asset Prices: Empirical Evi- dence}

Our main data set covers the 1985-2009 period for a sample of 31 countries which we refer to as our "G30" sample plus the United States. As a robustness check, we also a study a smaller dataset that contains only 11 developed countries (our "G10" sample plus the United States). ${ }^{2}$

\subsection{Innovation and Trade}

We use annual bilateral trade data at the product level (HS-6 digit and SITC-5 digit codes). The source of our data is the UN COMTRADE database. We compute the following international trade statistics. First, we collect data on the total volume of international trade from the foreign country $f$ to the domestic country $d, X_{f}^{d}$. Then, we decompose this data into the so called extensive margin (the number of products that are bilaterally traded across each country-pair, $N_{f}^{d}$ ) and intensive margin of trade (the amount of each product that is traded across countries, $\left.\bar{X}_{f}^{d} \equiv X_{f}^{d} / N_{f}^{d}\right)$. For our empirical

\footnotetext{
${ }^{2}$ The G30 samples includes Australia, Austria, Belgium, Canada, Denmark, Finland, France, Germany, Greece, India, Ireland, Italy, Japan, Malaysia, Mexico, Netherlands, New Zealand, Norway, Pakistan, Philippines, Poland, Portugal, Singapore, South Africa, Spain, Sweden, Switzerland, Taiwan, Thailand, United Kingdom, and United States. The G10 sample includes Australia, Canada, France, Germany, Japan, New Zealand, Norway, Sweden, Switzerland, United Kingdom, and United States.
} 
analysis, we normalize these measures of international trade sing the sum of the country pair gross domestic products.

We then collect data on innovation from the World Development Indicators Database of the World Bank. Following the literature, we measure the intensity of innovation as the fraction of each country's GDP that is invested into R\&D. Our hypothesis is that $\mathrm{R} \& \mathrm{D}$ in one country can diffuse to the rest of the world through trade in the products that embody such R\&D. Ideally, to test this hypothesis we would like to construct a measure of how much R\&D is embodied in each internationally traded product. To do that, we would require disaggregated data of $R \& D$ intensity at the product level, which is unfortunately unavailable for our sample of countries. To overcome this limitation in the data, we compute an indirect measure of R\&D embodied in trade using country level data for innovation. Specifically, we compute the proportion of R\&D from country $f$ that is embodied in the imports of country $d$, relative to the R\&D embodied in total imports of country $d$ from the rest of the world (where each exporter is indexed by $k$ ), as follows

$$
\frac{X_{f}^{d} S_{f}}{\sum_{k=1} X_{k}^{d} S_{k}},
$$

where $S_{k}$ represents the R\&D expenditures of country $k$. Similar measures can be obtained for R\&D embodied in each margin of trade. Details on the construction of these measures are in Appendix A.

\subsection{Financial Data}

We collect data on on stock market returns, exchange rate volatility, and currency excess returns. Our sources are Datastream and Ken's French website for stock market data, and Global Financial Data for nominal exchange rates and interest rates. We start from quarterly observations and build quarterly stock market returns and currency depreciation rates. To compute currency excess returns, we use data on the 3-month nominal interest rates. Stock market data is from Datastream and exchange rates and nominal interest rates are from Global Financial Data. Details on the construction of these measures are in Appendix A.

\subsection{Comovements}

In this Section we show that diffusion of R\&D through trade in varieties has strong implications for the dynamics of international asset prices. We proceed in two steps.

First, we look at whether general measures of trade across countries are correlated 
with international asset prices. Figures 1 and 2 reports the country-pair average of trade data for our entire 1985-2009 sample, for a total of 465 country pairs. They show that countries that trade more with each other, both at the extensive and intensive margins of trade have more correlated stock market returns and less volatile nominal exchange rates.

Figure 1: Stock Market Correlation and International Trade
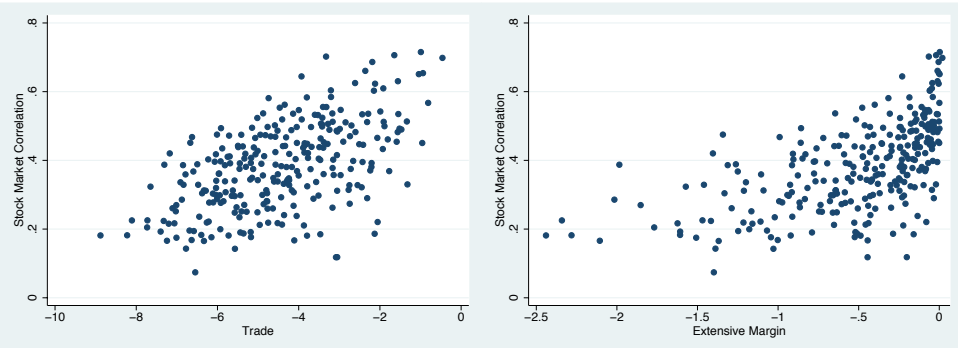

Figure 2: Exchange Rate Volatility and International Trade
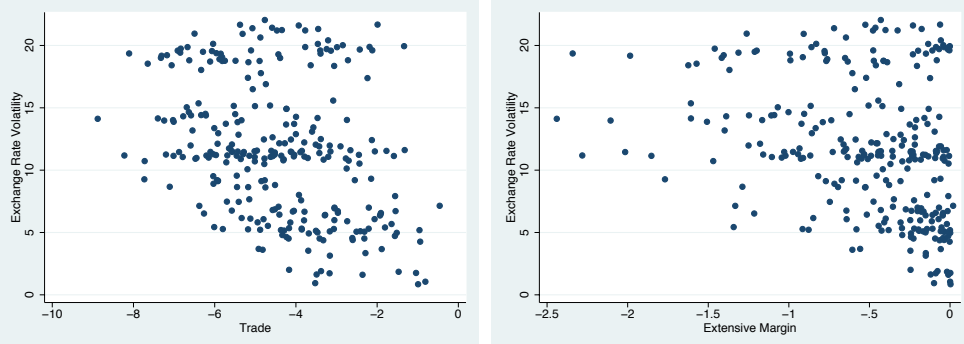

Although these figures go in favor of our hypothesis that R\&D diffuses across countries through trade in varieties, our general measures of international trade do not explicitly include information on how much R\&D is actually embodied in imports. Indeed, consider the case of a country that is importing many varieties from a not very innovative trading partner. In this case, Figures 1 and 2 would overstate the quantitative strength of our mechanism.

To overcome this issue, we use the proxies for $R \& D$ embodied in international trade that we introduced in Section 2.1. Figures 3 and 4 are consistent with our previous empirical results: i) the correlation of stock markets returns are stronger for those country pairs that rely more heavily on each other R\&D's, and ii) the volatility of currency depreciation rates are lower for those country pairs that rely more heavily on each other R\&D's. 
Figure 3: Stock Market Correlation and R\&D intensity of International Ttade

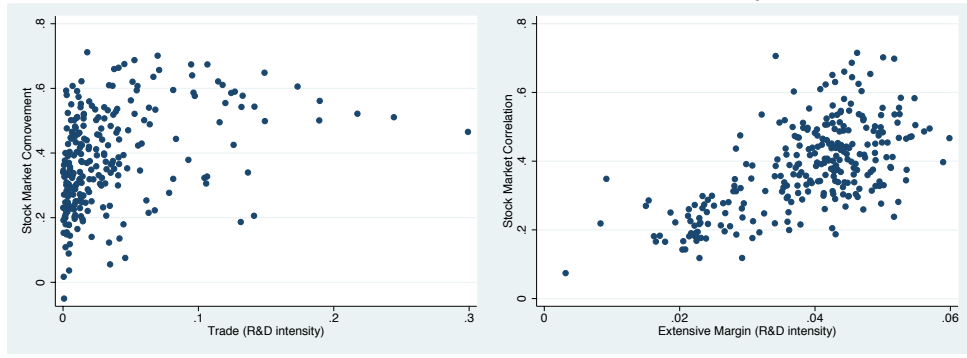

Figure 4: Exchnage Rate Volatility and R\&D intensity of International Trade
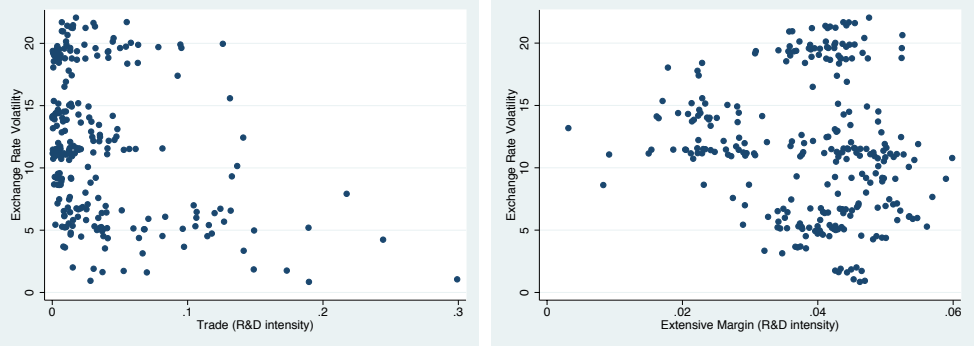

We complete our empirical analysis by exploring the role of our mechanism on currency carry trades. We find that, for any given country pair, the country that depends relatively more on its trading partner's R\&D has a currency that pays a positive risk premium. Take for example the case of Japan and New Zealand. We start by calculating the difference between our measures of Japan's dependence on New Zealand's R\&D and New Zealand's dependence on Japan's R\&D. Since Japan is one of the most innovative countries of our sample, this difference is negative. In addition, as is well known, the Yen-denominated return of the strategy "borrow Japanese Yen and invest in New Zealand Dollars" yields a positive excess return. This negative relation between the difference in R\&D dependence and currency excess returns is consistent across our sample of country pairs as shown in Figure 5 .

Figure 5: Foreign Exchange Excess Returns and International Trade
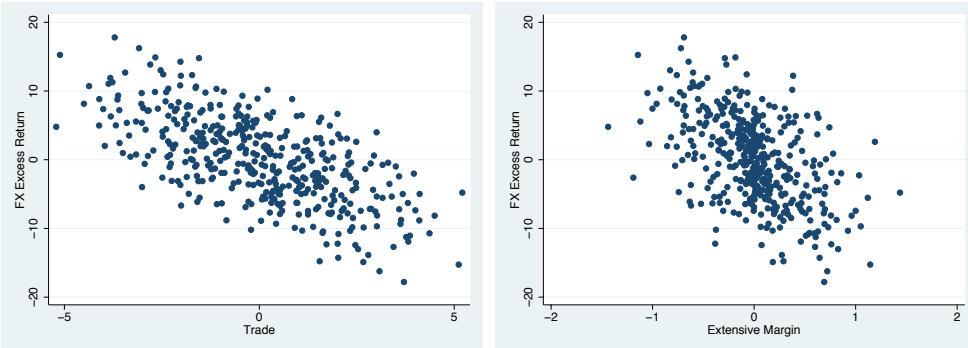

Consistently with the Figures above, Table 1 reports sample correlations between our 
measure R\&D intensity of the extensive margin and financial variables.

\begin{tabular}{lc} 
& EM(R\&D) \\
\hline Stock Market Corr & 0.50 \\
FX Carry & -0.24 (diff) \\
FX Depretiation Vol & -0.14 \\
\hline
\end{tabular}

Table 1: G20 countries (1985-2009)

\section{Model}

In this Section, we present a model of innovation and international diffusion of R\&D through trade in varieties that captures our empirical findings. Each country has a representative household with recursive preferences and consume a final good. A final producer uses labor, capital and a composite of intermediate goods that we call materials to produce the non-tradable final good that is used for consumption, investment in capital and investment in R\&D. Materials are produced with traded intermediate goods (varieties), both domestic and foreign, which are produced by monopolistic competitive firms. The production of materials feature a love-for-variety effect so that, holding expenditure constant, a higher number of varieties increases the productivity of the country. New varieties are introduced in each country through an endogenous process of innovation, and then spread exogenously across countries through a slow process of adoption. Endogenous innovation and adoption together with recursive preferences are the new features at the core of our mechanism. The model is closed with an international risk sharing condition,

Here below we describe the domestic economy $d$. The foreign economy $f$ is defined analogously.

\subsection{Households}

The domestic representative household has Epstein-Zin recursive preferences over consumption:

$$
U_{d, t}=\left\{(1-\beta) C_{d, t}^{\theta}+\beta\left(E_{t}\left(U_{d, t+1}^{1-\gamma}\right)\right)^{\frac{\theta}{1-\gamma}}\right\}^{\frac{1}{\theta}},
$$

where $\gamma$ is the CRRA, $\theta=\frac{1-\gamma}{1-\frac{1}{\psi}}$ and $\psi \equiv \frac{1}{1-\theta}$ is the IES. We assume that $\psi>\frac{1}{\gamma}$, so that the representative agent has a preference for early resolution of uncertainty and fears 
variations in the long-run prospects of the economy. The stochastic discount factor is given by

$$
M_{d, t+1}=\beta\left(\frac{C_{d, t+1}}{C_{d, t}}\right)^{\theta-1}\left(\frac{U_{d, t+1}}{E_{t}\left(U_{d, t+1}^{1-\gamma}\right)^{\frac{1}{1-\gamma}}}\right)^{1-\gamma-\theta},
$$

where the last term captures the agent's concerns over uncertainty in long-run growth. The household consumes, supplies labor to the final producers, and makes investment/saving decisions participating in complete international financial markets. Accordingly, her budget constraint is

$$
C_{d, t}+E_{t}\left[M_{d, t+1} \mathcal{A}_{d, t+1}\right]=W_{d, t} L_{d, t}+\mathcal{A}_{d, t}
$$

where $W_{d, t}$ is the wage rate, $L_{d, t}$ denotes hours worked, and $\mathcal{A}_{d, t}$ is the state contingent value of the household's financial wealth. Since there is no disutility of labor, the household supplies her entire endowment, which is normalized to one.

\subsection{Final Good Producers}

Domestic final producers are perfectly competitive, and use capital, $K_{d, t}$, labor, $L_{d, t}$, and a composite of domestic and foreign intermediate goods, $G_{d, t}$, to produce a non-traded final good $Y_{d, t}$ according to the following Cobb-Douglas production function:

$$
Y_{d, t}=\left(K_{d, t}^{\alpha}\left(\Omega_{d, t} L_{d, t}\right)^{(1-\alpha)}\right)^{(1-\xi)} G_{d, t}^{\xi}
$$

The composite good $G_{d, t}$ is defined as

$$
G_{d, t}=\left[\int_{i \in \Omega}\left(X_{d, i, t}^{d}\right)^{\nu} d i+\int_{j \in \Omega^{*}}\left(X_{f, j, t}^{d}\right)^{\nu} d j\right]^{\frac{1}{\nu}},
$$

where $X_{d, i, t}^{d}$ is the amount of domestically produced intermediate good $i$ that is used for final production in the domestic economy, $X_{f, j, t}^{d}$ is the amount of foreign produced intermediate good $j$ that is used for final production in the domestic economy, $\Omega\left(\Omega^{*}\right)$ is the mass of domestic (foreign) intermediate goods that is used by domestic final producers, and $\frac{1}{1-\nu}$ is the elasticity of substitution across intermediate goods with $\nu<1$.

Final producers choose capital, labor, investment, and intermediate goods to maximize shareholder value subject to the production technology (3). Formally, 


$$
\max _{\left\{I_{d, t}, L_{d, t}, K_{d, t+1}, X_{d, i, t}^{d}, X_{f, j, t}^{d}\right\}_{t \geq 0, i \in \Omega, j \in \Omega^{*}}} E_{0}\left[\sum_{t=0}^{\infty} M_{d, t} D_{d, t}\right],
$$

where firm's dividends are given by

$$
D_{d, t}=Y_{d, t}-I_{d, t}-W_{d, t} L_{d, t}-\int_{i \in \Omega} P_{d, i, t}^{d} X_{d, i, t}^{d} d i-\int_{j \in \Omega^{*}} P_{f, j, t}^{d} X_{f, i, t}^{d} d j
$$

Here, $M_{d, t}$ is the stochastic discount factor, $W_{d, t}$ is the wage rate, $I_{d, t}$ is investment in physical capital, $P_{d, i, t}^{d}$ is the price of a domestically produced intermediate good, and $P_{f, j, t}^{d}$ is the price of a foreign produced intermediate good that is used for domestic production. Both prices are expressed in units of the domestic producer's final good.

The law of motion for physical capital is given by

$$
K_{d, t+1}=(1-\delta) K_{d, t}+\Lambda\left(\frac{I_{d, t}}{K_{d, t}}\right) K_{d, t}
$$

where $\delta \in(0,1)$ is the depreciation rate and $\Lambda\left(\frac{I_{d, t}}{K_{d, t}}\right)$ captures convex capital adjustment costs. ${ }^{3}$

\subsection{Intermediate Good Producers}

In each country, a set of monopolistic competitive firms produces a differentiated good using final output according to a CRS production function (one unit of final output is used to produce one unit of the intermediate good). All intermediate producers produce with the same efficiency. They take as given the demand by final producers and set a price for their goods that is a constant markup over the marginal cost. Intermediate producers produce both for the domestic and foreign market. To sell the good abroad, they face an iceberg transport $\operatorname{cost} \tau$.

Every period, each domestic intermediate producer $i$ solves the following static profit maximization problem:

\footnotetext{
${ }^{3}$ Specifically, $\Lambda_{d, t} \equiv \Lambda\left(\frac{I_{d, t}}{K_{d, t}}\right)=\frac{\alpha_{1}}{\zeta}\left(\frac{I_{d, t}}{K_{d, t}}\right)^{\zeta}+\alpha_{2}$, as in Jermann (1998). The parameters $\alpha_{1}$ and $\alpha_{2}$ are chosen so that there are no adjustments costs in the steady state, and $\frac{1}{1-\zeta}$ is the elasticity of the investment rate with respect to Tobin's Q.
} 


$$
\begin{aligned}
\max _{P_{d, i, t}^{d}, P_{d, i, t}^{f *}} \Pi_{d, i, t} & \equiv \max _{P_{d, i, t}^{d}, P_{d, i, t}^{f *}}\left(\pi_{d, i, t}^{d}+\pi_{d, i, t}^{f}\right) \\
& =\max _{P_{d, i, t}^{d}} P_{d, i, t}^{d} \quad X_{d, i, t}^{d}\left(P_{d, i, t}^{d}\right)-X_{d, i, t}^{d} \quad\left(P_{d, i, t}^{d}\right) \\
& +\max _{P_{d, i, t}^{f *}}(\underbrace{P_{d, i, t}^{f} Q_{t}}_{P_{d, i, t}^{f *}}) X_{d, i, t}^{f}(\underbrace{P_{d, i, t}^{f} Q_{t}}_{P_{d, i, t}^{f *}})-X_{d, i, t}^{f}(\underbrace{P_{d, i, t}^{f} Q_{t}}_{P_{d, i, t}^{f *}}),
\end{aligned}
$$

where $\pi_{d, i, t}^{d}\left(\pi_{d, i, t}^{f}\right)$ are the profits from selling the domestic product at home (abroad), $P_{d, i, t}^{f^{*}}=P_{d, i, t}^{f} Q_{t}$ is the price, in domestic good units, of a domestically produced intermediate good that is being exported, and $Q_{t}$ is the real exchange rate, defined as the number of domestic final goods per one unit of foreign final good. ${ }^{4}$

In a symmetric equilibrium, we have that

$$
X_{d, i, t}^{d} \equiv X_{d, t}^{d} \quad P_{d, i, t}^{d} \equiv P_{d, t}^{d}=\frac{1}{\nu} \quad P_{d, j, t}^{f^{*}} \equiv P_{d, t}^{f *}=\frac{1}{\nu} \tau
$$

where $\frac{1}{\nu}$ is the markup.

\subsection{Innovation and Adoption}

\subsubsection{Innovation}

In each country innovators invest resources (final output) to introduce new prototypes of a product. If an innovator is successful, it starts producing the new good as an intermediate producer. Each domestic innovator $i$ chooses $S_{d, i, t}$ to maximize the present discounted value of future profits that it expects to obtain from selling the good to both domestic and foreign producers. The value of a prototype to innovator $i$ is given by

$$
V_{d, i, t}=\Pi_{d, i, t}+(1-\phi) E_{t}\left[M_{d, t+1} V_{d, i, t+1}\right]
$$

where $\phi$ is the exogenous probability that a new variety becomes obsolete.

In a symmetric equilibrium,

$$
V_{d, i, t} \equiv V_{d, t} \quad \Pi_{d, i, t} \equiv \Pi_{d, t} \quad \pi_{d, i, t}^{d} \equiv \pi_{d, t}^{d} \quad \pi_{d, i, t}^{f} \equiv \pi_{d, t}^{f},
$$

and the law of motion of new prototypes is

\footnotetext{
${ }^{4}$ We express real prices of the intermediate goods in units of the importers' final good. In particular, when the domestic (foreign) intermediate good is used for the production of the foreign (domestic) final output, we have $P_{d, t}^{f} \equiv \frac{1}{\nu} \tau Q_{t}^{-1}$ and $P_{f, t}^{d} \equiv \frac{1}{\nu} \tau Q_{t}$
} 


$$
N_{d, t+1}^{d}=\vartheta_{d, t} S_{d, t}+(1-\phi) N_{d, t}^{d}
$$

where

$$
\vartheta_{d, t}=\frac{\chi N_{d, t}^{d}}{S_{d, t}^{1-\eta}\left(N_{d, t}^{d}\right)^{\eta}}
$$

as in Comin and Gertler (2006), and $S_{d, t}=S_{d, i, t} N_{d, t}^{d}$ is total R\&D expenditure in the domestic country (in terms of the domestic final good).

Discounted future profits on patents are the payoff to innovators. Since the R\&D sector is competitive, the optimality condition for $\mathrm{R} \& \mathrm{D}$ investment is

$$
S_{d, t}=E_{t}\left[M_{d, t+1} V_{d, t+1}\right]\left(N_{d, t+1}^{d}-(1-\phi) N_{d, t}^{d}\right)
$$

or, equivalently,

$$
\frac{1}{\vartheta_{d, t}}=E_{t}\left[M_{d, t+1} V_{d, t+1}\right]
$$

We assume that every innovation that is produced in a country can immediately be used by the final producer of that country. Hence, $N_{d, t}^{d}$ is the stock of domestic intermediate products that are used by the domestic final producers. On the other hand, a new intermediate product can be sold abroad only after diffusing internationally. The process for international international diffusion of intermediate goods is introduced in the next Section.

\subsubsection{Adoption}

We assume that adoption is exogenous and that every period only a fraction $\vartheta_{f}^{d}$ of foreign intermediate goods can be used by the domestic final producer. The law of motion of foreign intermediate goods that can be used by the domestic final producer evolves according to

$$
N_{f, t+1}^{d}=\vartheta_{f}^{d}\left(N_{f, t}^{f}-\phi N_{f, t}^{d}\right)+\phi N_{f, t}^{d}
$$

where $N_{f, t}^{f}$ is the number of foreign produced intermediate goods and $N_{f, t}^{d}$ is the number of goods imported by the domestic economy. Notice that foreign intermediate goods are adopted at home with a one period lag, capturing the idea of slow international diffusion of R\&D. 


\subsection{Resource Constraint}

Final output is used for consumption, intermediate goods production and investment in $\mathrm{R} \& \mathrm{D}$. Thus the resource constraint is

$$
Y_{d, t}=C_{d, t}+I_{d, t}+S_{d, t}+N_{d, t}^{d} X_{d, t}^{d}+N_{d, t}^{f} X_{d, t}^{f}
$$

\subsection{Asset Prices}

\subsubsection{Exchange Rate and International risk sharing condition}

Given complete financial markets, the real exchange rate $Q_{t}$ evolves according to

$$
\frac{Q_{t+1}}{Q_{t}}=\frac{M_{f, t+1}}{M_{d, t+1}}
$$

Because of recursive preferences, the risk sharing mechanism is non standard as agents fear not only current shocks but also variation in future utility (see Equation (2)). Colacito and Croce (2013) provide a thorough analysis of this mechanism.

\subsubsection{The Stock Market}

Stocks are claims to all future dividends of all the firms in the economy. Domestic aggregate dividends $\mathcal{D}_{d, t}$ are the net payout of the production sector:

$$
\mathcal{D}_{d, t}=D_{d, t}+N_{d, t}^{d} \pi_{d, t}^{d}+N_{f, t}^{d} \pi_{f, t}^{d}-S_{d, t}
$$

\subsubsection{Currency Excess Returns}

TBA

\subsection{Equilibrium and Steady State}

This Section defines a symmetric equilibrium: a set of equations according to which all firms within a country behave symmetrically. For each country $i=(d, f)$, a general symmetric equilibrium is defined as an exogenous stochastic sequence of technology shocks $\left\{\Omega_{i, t}\right\}_{t=0}^{\infty}$, an initial vector $\left\{N_{d, 0}^{d}, N_{d, 0}^{f}, N_{f, 0}^{f}, N_{f, 0}^{d}, K_{d, 0}, K_{f, 0}\right\}$, a set of parameters $\{\beta, \theta, \gamma, \psi, \alpha, \ldots\}$, a sequence of aggregate prices $\left\{W_{i, t}, V_{i, t}, Q_{t}, q_{i}, t\right\}_{t=0}^{\infty}$, a sequence of intermediate good prices $\left\{P_{d, t}^{d}, P_{d, t}^{f}, P_{f, t}^{f}, P_{f, t}^{d}\right\}_{t=0}^{\infty}$, a sequence of aggregate quantities $\left\{Y_{i, t}, G_{i, t}, C_{i, t}, I_{i, t}, L_{i, t}, S_{i, t}\right\}_{t=0}^{\infty}$, quantities of intermediate goods $\left\{X_{d, t}^{d}, X_{d, t}^{f}, X_{f, t}^{f}, X_{f, t}^{d}\right\}_{t=0}^{\infty}$, 
a sequence of profits $\left\{\Pi_{d, t}, \Pi_{f, t}, \pi_{d, t}^{d}, \pi_{d, t}^{f}, \pi_{f, t}^{f}, \pi_{f, t}^{d}\right\}_{t=0}^{\infty}$, and laws of motion $\left\{N_{d, t+1}^{d}, N_{d, t+1}^{f}, N_{f, t+1}^{f}, N_{f, t+1}^{d}, K_{i, t+1}\right\}_{t=0}^{\infty}$ so that

- The state variables satisfy the law of motion

- The endogenous variables solve the producers', innovators', and households problems

- The resource constraint is satisfied

- Prices are such that all markets clear

It can be shown that the economy has a balanced growth path in which all countries grow at the same rate and are symmetric in levels.

\section{Discussion}

\subsection{The mechanism}

In this section we present the expression for TFP that is central to our mechanism. Domestic TFP can be expressed as

$$
Z_{d, t} \equiv \Omega_{t}(\bar{A})^{\frac{1}{1-\alpha}}\left[N_{d, t}^{d}+\left(\tau_{t} Q_{t}\right)^{\frac{\nu}{\nu-1}} N_{f, t}^{d}\right]
$$

where $\bar{A} \equiv(\xi \nu)^{\frac{\xi}{1-\xi}}$.

Taking logs,

$$
\log Z_{d, t}=\log \Omega_{t}+\log \left\{(\bar{A})^{\frac{1}{1-\alpha}}\left[N_{d, t}^{d}+\left(\tau_{t} Q_{t}\right)^{\frac{\nu}{\nu-1}} N_{f, t}^{d}\right]\right\}
$$

Hence, TFP has both an exogenous and an endogenous component.

$$
\log (T F P)=\log \left(T F P^{E X O}\right)+\log \left(T F P^{E N D O}\right)
$$

with

$$
\log \left(T F P^{E X O}\right)=\log \Omega_{t}
$$

and

$$
\log \left(T F P^{E N D O}\right)=\log \left\{(\bar{A})^{\frac{1}{1-\alpha}}\left[N_{d, t}^{d}+\left(\tau_{t} Q_{t}\right)^{\frac{\nu}{\nu-1}} N_{f, t}^{d}\right]\right\}
$$

The exogenous component of TFP is given by the stochastic process $\Omega_{t}$; the endogenous component, which plays a crucial role in our mechanism, depends on the number of varieties that have been produced domestically, $N_{d, t}^{d}$, and the number of varieties that have 
been produced in the foreign country and are already adopted at home, $N_{f, t}^{d}$. We refer to $N_{d, t}^{d}$ as the domestic component of endogenous TFP and $\left(\tau_{t} Q_{t}\right)^{\frac{\nu}{\nu-1}} N_{f, t}^{d}$ as the foreign component of endogenous TFP. From the process of innovation and adoption explained in Section 3.4 it can be shown that endogenous TFP is positively affected by the R\&D done in the domestic country and the foreign R\&D embodied in imports. Thus, foreign $R \& D$ diffuses across countries through trade in varieties, generating a positive comovement of TFP across countries. This process of innovation and international diffusion makes a positive productivity shock have a persistent effect on the productivity of a country and its trading partner, which helps to explain the positive correlation of quantities. ${ }^{5}$ For this channel to have a quantitatively relevant effect on asset prices we need to understand the role of recursive preferences.

For asset prices, the main mechanism works as follows. Risky growth through endogenous innovation and recursive preferences determines the optimal level of $\mathrm{R} \& \mathrm{D}$, and therefore the level of current and future expected growth. As mentioned earlier, innovations then spread across countries through a process of technology adoption that we measure with trade in varieties. Risky growth has a first order impact on the stock market and governs its international correlation structure. To see this, recall that aggregate dividends in each country (eq. (18)) are given by the present discounted value of the future profits of all the firms operating in that country. Precisely, we decompose the return of the stock market into four components:

1. Price of installed capital: $P_{t}^{k} K_{t}$

2. Value of adopted domestic technologies (adopted by both domestic and foreign firms)

$$
N_{d t}^{d}\left(V_{d t}^{d}-\pi_{d t}^{d}\right)+N_{d t}^{f}\left(V_{d t}^{f}-\pi_{d t}^{f}\right)
$$

3. Value of existing not-yet adopted technologies

$$
\left(N_{d t+1}^{d}-(1-\phi) N_{d t}^{f}\right) J_{d t+1}^{f}
$$

where

$$
J_{d t}^{f}=0+\vartheta_{d}^{f} V_{d, t+1}^{f}+\left(1-\vartheta_{d}^{f}\right) J_{d, t+1}^{f}
$$

4. Value of all the technologies that we expect to develop in the future.

(a) Value of all new technologies arriving in the future that will be sold instanta-

\footnotetext{
${ }^{5}$ See Liao and Santacreu (2013) for a cross-sectional analysis of the mechanism
} 
neously in the the domestic country

$$
\sum_{i=0}^{\infty}\left(N_{d, t+i+1}^{d}-(1-\phi) N_{d t+i}^{d}\right) V_{d, t+i+1}^{d}
$$

(b) Value of future domestic technologies that will potentially be sold in the foreign market

$$
\sum_{i=0}^{\infty}\left(N_{d, t+i+1}^{d}-(1-\phi) N_{d t+i}^{f}\right) J_{d, t+i+1}^{f}
$$

When we calibrate our model, we find that the last component is the main contributor to the high correlation in the stock market across countries. It is the consequence of the common factor generated by the international diffusion mechanism. As described earlier, this common factor, which drives future expected growth, is highly persistent both within and across countries. Given the recursive nature of the preferences, agents fear variations in the future prospects of the economy, and attach to this common component a large price of risk. ${ }^{6}$

Therefore, while realized quantities are primarily driven by realized levels of innovation and technology adoption of foreign innovations on the current output growth, the comovement in asset prices is mainly driven by the prospects of future economic growth. This mechanism was first emphasized in a reduced form model by Colacito and Croce (2011). Our contribution is to provide an economic mechanism that drives the wedge between comovement in quantities and asset prices.

\subsection{Reduced Form}

Following the seminal paper of Bansal and Yaron (2004), the long-run risk literature of asset pricing has forcefully argued in favor of the existence of a small predictable risk factor driving the growth prospects of the economy. A long-run-risk explanation of asset pricing puzzles requires this factor to be: i) highly autocorrelated within the country, and ii) highly correlated across countries. When paired with recursive preferences, a strong persistence within-country delivers a large equity premium with a sensible risk aversion parameter (Bansal, Kiku, and Yaron (2012)). On the other hand, a high correlation across countries is instrumental in obtaining a high cross-country correlation in the marginal rate of substitution - and thus an exchange rate process that is not too volatile - while still keeping the cross-country correlation of realized consumption growth close to the low levels we observe in the data (Brandt, Cochrane, and Santa-Clara (2006)).

\footnotetext{
${ }^{6}$ This results holds when agents prefer an early resolution of uncertainty, as it is the case in our paper.
} 
In this section, we describe a reduced-form model that captures our novel mechanism of international spillovers of long-run risk. In Section 3, we introduce our benchmark general equilibrium model, in which we endogenize such mechanism. Let the home and foreign long run risk processes be described by the following two-dimensional autoregressive process $z_{t} \equiv\left(z_{t}^{H}, z_{t}^{F}\right)^{\prime}$ :

$$
z_{t}=\Phi z_{t-1}+\Sigma \epsilon_{t}
$$

Consistently with our benchmark model, we restrict our attention to a symmetric calibration in which the autocorrelation matrix $\Phi$ and the variance-covariance matrix $\Sigma$ are given by

$$
\Phi=\left(\begin{array}{cc}
\varphi & \varphi_{H}^{F} \\
\varphi_{H}^{F} & \varphi
\end{array}\right) \quad ; \quad \Sigma=\left(\begin{array}{cc}
\sigma & 0 \\
0 & \sigma
\end{array}\right)
$$

For stationarity, the eigenvalues of $\Phi$ must be within the unit circle. The $\epsilon \equiv\left(\epsilon^{H}, \epsilon^{F}\right)^{\prime}$ innovations are i.i.d. and normally distributed with zero mean and unit variance. We allow for a non zero cross-country correlation in innovations and define $\rho_{z} \equiv \operatorname{Corr}\left(\epsilon^{H}, \epsilon^{F}\right)$. To showcase the mechanism of our paper, we analyze two versions of equation (19), both of which generate the required correlation structure of long run risk. We argue that the second describes a more plausible economics mechanism.

First, we consider a univariate long run risk specification, in which we shut down the off-diagonal elements of the autocorrelation matrix $\Phi$, by imposing $\varphi_{H}^{F}=0$. In this case, lagged values of $z^{F}\left(z^{H}\right)$ do not affect current values of $z^{H}\left(z^{F}\right)$. With this restriction in place, it is straightforward to show that $\operatorname{Corr}\left(z_{t}^{H}, z_{t-1}^{H}\right)=\operatorname{Corr}\left(z_{t}^{F}, z_{t-1}^{F}\right)=\varphi$ and $\operatorname{Corr}\left(z_{t}^{H}, z_{t}^{F}\right)=\rho_{z}$. Therefore, for long run risk to be highly correlated both within and across countries, it must be that $\varphi \approx 1$ and $\rho_{z} \approx 1$. Many papers have studied the nature of the autocorrelation coefficient $\varphi$ and its effect on asset prices. Here, for the univariate case, we focus on the cross-country correlation coefficient $\rho_{z}$. A high cross-country correlation between the home and foreign long-run risk components can be obtained exclusively by assuming a high cross-country correlation in the long run innovations, $\epsilon^{H}$ and $\epsilon^{F}$. This is the solution adopted by Bansal and Shaliastovich (2009) and Colacito and Croce (2011). In sum, for a univariate specification to work, one must assume both a high autocorrelation coefficient and a high cross-country correlation in long-run innovations.

The second specification we consider a bivariate long run risk process, which represents the reduced form of the mechanism in our benchmark model. This specification features an international spillover effect, which we capture by allowing for non-zero off diagonal 
elements of $\Phi\left(\varphi_{H}^{F} \neq 0\right)$. Therefore, lagged values of $z^{F}\left(z^{H}\right)$ do affect current realizations of $z^{H}\left(z^{F}\right)$. Now, to isolate the effect of the interaction term on the correlation structure of home and foreign long run risk, we shut down the cross-country correlation in the $\epsilon$ shocks and impose $\rho_{z}=0$. With this exercise we want to answer the following question: How strong must the interaction effect be in order to obtain the high cross-country correlation between $z^{H}$ and $z^{F}$ that is prescribed by the long run risk literature? The answer will give us an idea of the quantitative impact of the international spillover mechanism that we propose in our benchmark model. ${ }^{7}$

We find that with a bivariate long run risk specification we can achieve a high cross country correlation for relatively small values of the interaction parameter. For values as small as 0.05 , the cross-country correlation is 0.80 . For values larger than 0.30 , the correlation is above 0.96, as typically assumed by the international finance literature on long run risks.

In our general equilibrium model, international adoption of domestically developed intermediate goods endogenously generates a strong comovement between home and domestic total factor productivity. Crucially, the only exogenous shocks of our model, which we label short run productivity shocks, are independent across countries, as captured by the restriction $\rho_{z}=0$ in the reduced form example of this section.

\section{$5 \quad$ Quantitative Results}

In this Section we perform a numerical exercise to show the main mechanism of our model. In our baseline calibration (which we label MAIN throughout this Section), we borrow our parameters from Kung and Schmid (2011), calibrate the coefficient of international adoption $\vartheta$ to 0.015 using data on traded varieties, and the iceberg transport cost $\tau$ to 1.2 to match relevant moments of international trade. The simulated parameters are reported in Table 2.

\footnotetext{
${ }^{7}$ While conducting the exercise, we tweak the $\varphi$ parameter, our only degree of freedom, to obtain a very high within country autocorrelation of $z^{H}$ and $z^{F}$, as prescribed by the long run risk literature.
} 


\begin{tabular}{lrr}
\hline \hline Parameter & Symbol & Baseline Value \\
\hline & & \\
Risk Aversion & $\gamma$ & 10 \\
IES & $\psi$ & 1.5 \\
Subjective Discount Factor & $\beta$ & $0.984^{1 / 4}$ \\
\hline Capital Share & $\alpha$ & 0.35 \\
Share of Materials & $\xi$ & 0.5 \\
Autocorrelation of $\Omega$ & $\rho_{a}$ & $0.95^{1 / 4}$ \\
Depreciation of capital stock & $\delta$ & 0.02 \\
Scale Parameter & $\chi$ & 0.4240 \\
Innovation Obsolence Rate & $\phi$ & 0.0375 \\
Elasticity of Innovation wrt R\&D & $\eta$ & 0.83 \\
Volatility of exogenous shock & $\sigma$ & $1.00 \%$ \\
\hline Inverse Markup & $\nu$ & 0.9 \\
Shipping Cost & $\tau$ & 1.2 \\
International Adoption Parameter & $\vartheta_{d}^{f}$ & 0.015 \\
\hline
\end{tabular}

Table 2: Calibrated Parameters

We then simulate the model and compute our moments of interest. The results are reported in Table 3. Our model has the ability to capture the high correlation in asset returns we observe in the data, the lower level of correlation in quantities, and several other important international asset pricing facts. The cross-country correlation of consumption growth is 0.20 , which is close to the average of 0.25 that we observe in the data; the correlation of stock market returns is 0.82 , also broadly consistent with the empirical evidence. The exchange rate volatility is around $7 \%$ in the model and $10 \%$ in the data. The results crucially depend on the recursive nature of preferences: with CRRA preferences, the model fails to account for the correlation in quantities, or in asset returns, or both.

In order to highlight the strength of our mechanism, we increase the speed of adoption to $\vartheta=0.025$ and study the change in the cross country moments of asset returns and quantities. The findings corroborate our intuition: when adoption is faster, the correlation of consumption growth and in stock market returns across countries is higher, and the volatility of the exchange rate depreciation is lower. These trends are consistent with the figures presented in Section 2 . 


\begin{tabular}{|c|c|c|c|c|}
\hline Moment & Data & $\vartheta=0.015$ & $\vartheta=0.025$ & CRRA \\
\hline$\sigma(\Delta c)$ & 1.42 & 1.67 & 1.62 & 1.97 \\
\hline$A C F_{1}\left(E_{t} \Delta z_{t+1}\right)$ & & 0.9832 & 0.9838 & 0.963 \\
\hline$A C F_{1}\left(E_{t} \Delta c_{t+1}\right)$ & & 0.9865 & 0.9869 & 0.914 \\
\hline $\operatorname{Corr}\left(\Delta c, \Delta c^{*}\right)$ & 0.25 & 0.2030 & 0.2800 & 0.980 \\
\hline$E\left(r_{f}\right)$ & 1.25 & 1.45 & 1.46 & 5.38 \\
\hline $\operatorname{Corr}\left(m, m^{*}\right)$ & & 0.9997 & 0.9998 & 0.9802 \\
\hline $\operatorname{Corr}\left(r_{f}, r_{f}^{*}\right)$ & 0.64 & 0.708 & 0.850 & 0.850 \\
\hline $\operatorname{Corr}\left(r_{m}-r_{f}, r_{m}^{*}-r_{f}^{*}\right)$ & 0.70 & 0.823 & 0.859 & -0.786 \\
\hline$\sigma(\Delta q)$ & 8.82 & 7.00 & 5.88 & 12.0 \\
\hline
\end{tabular}

Table 3: Experiment: Varying the speed of adoption

Finally, we conduct several exercises to understand the importance of our mechanism. We consider four cases: (i) Exogenous R\&D (EXO); (ii) Endogenous R\&D and very slow international adoption (ENDO-SLOW) (iii) Exogenous R\&D and very slow international adoption (EXO-SLOW); and (iv) Baseline model with CRRA preferences (CRRA). Table 4 reports the results. Four patterns emerge. First, with CRRA preferences, the correlation of consumption growth is too high. Second, the international adoption mechanism appears to be the main driver of the comovements in quantities. Third, the endogenous innovation channel is the main driver of stock market return correlation. Fourth, our models needs substantial international adoption of foreign R\&D to limit the volatility of the depreciation rate.

The failure of the CRRA calibration speaks to the inability of a model without recursive preferences to create a significant wedge between the cross country comovements of quantities and asset returns. As for quantities, we find that, without endogenous innovation (EXO), the correlation of consumption growth across countries is lower than in our baseline calibration (0.04 versus 0.20$)$ but remains positive as a consequence of the international adoption mechanism. However, once we shut down the international adoption channel (EXO-SLOW and ENDO-SLOW) the correlation in consumption growth becomes negative. A striking result is that, in this case, the exogenous or endogenous nature of R\&D has no impact on the value of this correlation (which is around -0.008 in both cases).

The results on the correlation of stock markets returns across the four calibrations show that the international adoption channel plays a quantitatively small role. Indeed, if 
we shut this channel the correlation remains high at 0.78 , only slightly lower than the 0.82 value that we obtain in our baseline calibration. Finally, with complete financial markets, the volatility of the depreciation rate is tightly linked to the correlation of the stochastic discount factors (eq. 17), which is higher when international adoption is high.

Taken together, our results confirm that we need both endogenous risky growth through $\mathrm{R} \& \mathrm{D}$ and international adoption to jointly match the comovements of quantities and asset market returns across countries.

\begin{tabular}{lcrrr}
\hline \hline Moment & EXO & ENDO-SLOW & EXO-SLOW & CRRA \\
\hline & & & & \\
$\operatorname{Corr}\left(\Delta c, \Delta c^{*}\right)$ & 0.0437 & -0.0086 & -0.0081 & 0.9080 \\
$\operatorname{Corr}\left(r_{m}-r_{f}, r_{m}^{*}-r_{f}^{*}\right)$ & 0.1360 & 0.7798 & 0.1062 & -0.786 \\
$\sigma(\Delta q)$ & 9.62 & 26.2 & 11.2 & 12.0 \\
\hline
\end{tabular}

Table 4: The Mechanism

\section{Conclusion}

The international macroeconomics and finance literature has had a hard time reconciling the joint dynamics of equilibrium quantities and asset prices. Among the most significant puzzles, and contrary to the prediction of standard real business cycle models, cross country correlations in macroeconomic quantities are significantly lower than cross country correlation in asset prices, exchange rates are volatile and appear to be disconnected from fundamentals, and uncovered interest parity is systematically violated. We have proposed a mechanism that may help reconcile these facts. Our mechanism features recursive preferences, endogenous $R \& D$ and international adoption through trade in varieties. After showing some empirical evidence in favor of this mechanism, we have developed a model that captures the main features of the data. A numerical exercise shows the importance of adding these channels to standard international macroeconomic models. 


\section{References}

Bansal, R., D. Kiku, and A. Yaron (2012, August). Risks for the long run: Estimation with time aggregation. Working Paper 18305, National Bureau of Economic Research.

Bansal, R. and I. Shaliastovich (2009). A long-run risks explanation of predictability puzzles in bond and currency markets. Working Paper.

Bansal, R. and A. Yaron (2004, 08). Risks for the long run: A potential resolution of asset pricing puzzles. Journal of Finance 59(4), 1481-1509.

Brandt, M. W., J. H. Cochrane, and P. Santa-Clara (2006, May). International risk sharing is better than you think, or exchange rates are too smooth. Journal of Monetary Economics 53(4), 671-698.

Broda, C., J. Greenfield, and D. Weinstein (2006, September). From groundnuts to globalization: A structural estimate of trade and growth. NBER Working Papers 12512, National Bureau of Economic Research, Inc.

Colacito, R. and M. M. Croce (2011). Risks for the long run and the real exchange rate. Journal of Political Economy 119(1), 153 - 181.

Colacito, R. and M. M. Croce (2013). International asset pricing with recursive preferences. The Journal of Finance 68(6), 2651-2686.

Comin, D. and M. Gertler (2006, June). Medium-term business cycles. American Economic Review 96(3), 523-551.

Croce, M. M., T. T. Nguyen, and L. Schmid (2013). Global entropy. Available at SSRN 2396646 .

Jermann, U. J. (1998). Asset pricing in production economies. Journal of Monetary Economics 41(2), 257-275.

Kung, H. and L. Schmid (2011). Innovation, growth and asset prices. Working Paper Duke University.

Lewis, K. K. (1995). Puzzles in international financial markets. Volume 3 of Handbook of International Economics, pp. 1913 - 1971. Elsevier.

Liao, W. and A. M. Santacreu (2013). The trade comovement puzzle and the margins of international trade. Available at SSRN 2422179.

Obstfeld, M. and K. Rogoff (2000, July). The six major puzzles in international macroeconomics: Is there a common cause? Working Paper 7777, National Bureau of Economic Research. 
Romer, P. M. (1990). Endogenous technological change. Journal of political Economy, S71-S102.

Santacreu, A. M. (2014). Innovation diffusion and trade: Theory and measurement. INSEAD Working Paper. 


\section{Appendices}

\section{A Trade Data, Asset Prices, and Comovements}

In this note, we describe trade data and asset prices and construct the measures relevant to our analysis.

\section{A.1 Trade Data}

The source of our trade data is UN COMTRADE. We collect product data at the 6-digit level of disaggregation. The data is annual and covers the 1985-2009 period. We focus on the trade that occurs between the importer $i$ (identified with its IISCODE) and the exporter $j$ (identified by its EISCODE), and collect data on the kind of product that is traded (the 6 digits identifying it) and the dollar value of the trade in each product (the per-product trade value).

Preliminary stats: calculate the fraction of world trade and world GDP that is accounted for by the countries in our sample. For the entire list, refer to the paper.

From this data, we construct the following measures:

\section{Step 1:}

- Trade Intensity $(i, j): T I_{i, j}$, i.e. the sum of the trade value of all the products

- Extensive margin $(i, j): E M_{i, j}$, i.e. the number (the"count") of different kinds of good imported by country $i$ from country $j$

- Intensive Margin $(i, j): I M_{i, j}=T I_{i, j} / E M_{i, j}$, i.e. "how much", in dollars, country $i$ is trading on average for each product imported from country $j$

In order to compare these numbers across country pairs, we normalize them taking into account each country's GDP. In particular, we define the normalized measures as

$$
\begin{gathered}
\tilde{T} I_{i, j}=\frac{T I_{i, j}}{G D P_{i}+G D P_{j}} \\
E M_{i, j}=E M_{i, j} \\
I \tilde{M}_{i, j}=\frac{\tilde{T} I_{i, j}}{E M_{i, j}}
\end{gathered}
$$

Note: this country pair is ordered: $i$ is the importer and $j$ is the exporter, i.e., $\tilde{T} I_{i, j}$ will usually be different from $\tilde{T} I_{j, i}$

Aside: we want to make sure that the relationship $\tilde{T} I_{i, j}=\tilde{E M} \tilde{M}_{i, j} I \tilde{M}_{i, j}$ holds, so that, taking logs, we can easily run linear regressions. 


\section{Step 2:}

For each ordered $(i, j)$ and $(j, i)$ country pair, we construct a measure of the overall strength of their trade, their trade linkage, as follows

$$
\begin{gathered}
\tilde{T} I_{i, j}^{l i n k}=\tilde{T} I_{i, j}+\tilde{T} I_{j, i}=\frac{T I_{i, j}+T I_{j, i}}{G D P_{i}+G D P_{j}} \\
E \tilde{M}_{i, j}^{l i n k}=E \tilde{M}_{i, j}+\tilde{E M_{j, i}} \\
I \tilde{M}_{i, j}^{l i n k}=\frac{\tilde{T} I_{i, j}^{l i n k}}{E M_{i, j}^{l i n k}}
\end{gathered}
$$

These measures will be useful to analyse the relation between trade and i) stock market correlations, and ii) exchange rate volatility.

\section{Step 3:}

For each ordered $(i, j)$ and $(j, i)$ country pair, we construct a measure of the difference of their trade dependance on each other.

$$
\begin{gathered}
\tilde{T} I_{i, j}^{d i f f}=\tilde{T} I_{i, j}-\tilde{T} I_{j, i} \\
E M_{i, j}^{d i f f}=\tilde{E M_{i, j}-E M_{j, i}} \\
I \tilde{M}_{i, j}^{d i f f}=I \tilde{M}_{i, j}-I \tilde{M}_{j, i}
\end{gathered}
$$

These measures will be useful to analyse the relation between trade and iii) excess currency returns.

\section{Step 4:}

For the measures above, we calculate their R\&D intensity. In order to do so, we collect data on the percentage of each country's GDP that comes from expenditure in R\&D. We obtain the R\&D intensity of the trade intensity, of the extensive margin, and of the intensive margin as follows ( $k$ indexes the countries from which country $i$ is importing):

$$
\begin{gathered}
\tilde{T I_{i, j}^{R \& D}}=\frac{T I_{i, j} \% R \& D_{G D P(j)}}{\sum_{k} T I_{i, k} \% R \& D_{G D P(k)}} \\
E M_{i, j}^{R \& D}=\frac{E M_{i, j} \% R \& D_{G D P(j)}}{\sum_{k} E M_{i, k} \% R \& D_{G D P(k)}}
\end{gathered}
$$




$$
I \tilde{M}{ }_{i, j}^{R \& D}=\frac{\tilde{T} I_{i, j}^{R \& D}}{E M_{i, j}^{R \& D}}
$$

\section{Step 5:}

We obtain the R\&D intensity of our linkage and difference measures as follows:

$$
\begin{aligned}
& \tilde{T} I_{i, j}^{l i n k, R \& D}=\tilde{T} I_{i, j}^{R \& D}+\tilde{T} I_{j, i}^{R \& D} \\
& \tilde{E M}_{i, j}^{l i n k, R \& D}=\tilde{E M}_{i, j}^{R \& D}+E \tilde{M}_{j, i}^{R \& D} \\
& I M_{i, j}^{l i n k, R \& D}=\frac{\tilde{T} I_{i, j}^{l i n k, R \& D}}{E M_{i, j}^{l i n k, R \& D}} \\
& \tilde{T} I_{i, j}^{d i f f, R \& D}=\tilde{T} I_{i, j}^{R \& D}-\tilde{T} I_{j, i}^{R \& D} \\
& \tilde{E M}_{i, j}^{d i f f, R \& D}=\tilde{E M}_{i, j}^{R \& D}-\tilde{E M}_{j, i}^{R \& D} \\
& I \tilde{M}_{i, j}^{d i f f, R \& D}=I \tilde{M}_{i, j}^{R \& D}-I \tilde{M}_{j, i}^{R \& D}
\end{aligned}
$$

\section{Step 6:}

The data above is annual. The analysis will be done on averages. We consider: i) 5-years non-rolling averages, and ii) the 1985/2009 sample average.

\section{A.2 Asset Prices}

We consider three statistics for asset prices: the cross country correlation in stock market returns, the volatility of the currency depreciation rate, and the excess return on the carry trade (the "borrow in the home currency and invest in the foreign currency). For consistency with our theoretical model, we focus on quarterly observations. The period covered is $1985 / 2009$, and the sources are Datastream and Ken French's website for the stock market data, and Global Financial Data for nominal interest rates and exchange rates. Precisely, for each quarter, we observe: i) the stock market level of a broad index, ii) the 3-month nominal interest rate (usually a Treasury), iii) the nominal exchange rate level, defined as number of units of domestic currency per one unit of foreign currency.

From this data, we construct the following measures: 


\section{Step 1: Stock Market}

- Quarterly log stock market returns for country $i$ : $r_{i, t}^{s}=s_{i, t}-s_{i, t-1}$, where $s_{i, t}$ is the $\log$ stock market level at time $t$ for country $i$

- Cross country stock market return correlations: $\operatorname{Corr}\left(r_{i, t}^{s}, r_{j, t}^{s}\right)$, both for 5-year non-rolling samples and for the entire sample

\section{Step 2: Exchange Rate}

- Quarterly $\log$ depreciation rate for currency $i$ w.r.t. currency $j: \Delta e_{i, t}^{j}=e_{i, t}^{j}-e_{i, t-1}^{j}$, where $e_{i, t}^{j}$ is the log exchange rate level at time $t$ for country $i$ (remember: it's in number of units of currency $i$ per one unit the $j$ currency)

- Volatility of currency $i$ depreciation rate w.r.t. currency $j: \operatorname{Vol}\left(\Delta e_{i, t}^{j}\right)$, both for 5-year non-rolling samples and for the entire sample

\section{Step 3: Carry trade}

- Quarterly log excess returns on"going long" the foreign currency: $r x_{i, t+1}^{j}=i_{j, t}-i_{i, t}+$ $\Delta e_{i, t+1}^{j}$, where $r x_{i, t+1}^{j}$ is the $i$ currency denominated realized excess return at time $t+1$ for entering, at time $t$, the strategy "borrow at home at $i_{i, t}$, and invest abroad at $i_{j, t}$ "

- Averages of quarterly $r x_{i, t+1}^{j}$ : both 5 -year non rolling and for the entire sample 